\title{
A Theory of International Conflict Management and Sanctioning *
}

\author{
Nuno R. Garoupa ${ }^{\dagger}$ \\ Universitat Pompeu Fabra, Barcelona \\ João E. Gata ${ }^{\ddagger}$ \\ Instituto Superior de Gestão, Lisbon
}

June 2000

\footnotetext{
${ }^{*}$ We are grateful to an anonymous referee, Steve Brams, and Patrick James for helpful suggestions. We also thank the participants at the 1998 American Public Choice Society Meetings in New Orleans, at the 1998 European Public Choice Society Meetings at the University of Göteborg, and at the 1998 Lisbon International Conference on Defence Economics and Security in Mediterranean and Sub-Saharan Countries, for their several comments. The usual disclaimer applies.

${ }^{\dagger}$ Assistant Professor, Department d'Economia i Empresa, Universitat Pompeu Fabra, Ramon Trias Fargas 25-27, 08005 Barcelona, Spain. Phone: 34-93-542 2639. Fax: 34-93542 1746. Email: nuno.garoupa@econ.upf.es

${ }^{\ddagger}$ Professor of Economics, Instituto Superior de Gestão, Ave. Vitorino Nemésio 5, P1750-306 Lisboa, Portugal. Phone: 351-217570053. Email: jgata@isg.pt
} 


\begin{abstract}
In this paper we analyze sanctioning policies in international law. We develop a model of international military conflict where the conflicting countries can be a target of international sanctions. These sanctions constitute an equilibrium outcome of an international political market for sanctions, where different countries trade political influence. We show that the level of sanctions in equilibrium is strictly positive but limited, in the sense that higher sanctions would exacerbate the military conflict, not reduce it. We then propose an alternative interpretation to the perceived lack of effectiveness of international sanctions, by showing that the problem might not be one of undersanctioning but of oversanctioning.
\end{abstract}

Keywords: conflict management, international sanctions, arms embargo, international political market, pressure groups.

JEL Classification: C72, D74, K33 


\section{Introduction}

There has been a long debate in the political and economic literature on the merits of imposing economic or military sanctions on countries violating certain rules governing international behavior. The goal of these sanctions is to produce in the target country a desired political change. However, some scholars have put forth the view that sanctions can be ineffective or even counterproductive - see e.g. Pape (1997). Their arguments have included the perverse political responses in the target country to the perceived 'unwarranted' third party interference represented by international sanctions, such as exacerbated nationalism or xenophobic behavior - a 'rally round the flag' type of behavior - or the likely punishment of innocent individuals in the target country who are not responsible for their government's policy see White (1994) for a survey of these arguments.

In the context of a military conflict between two countries subject to sanctions imposed by third parties, our paper explores the effectiveness of sanctioning within a game theoretic model where sanctions are not taken exogenously but generated endogenously. We show that the level of sanctions in equilibrium is strictly positive but limited, in the sense that higher sanctions would exacerbate the military conflict, not reduce it. This result comes from the interaction between all players in the international political market, and constitutes an alternative explanation to the two types of arguments discussed above. ${ }^{1}$

Our starting point is the observation that individuals in local jurisdictions, with the possible exception of legislators and judges, perceive their ability to actually influence the law under which their acts will be judged to be very small. Suppose an individual subject to a particular judicial system considers whether or not to commit an act which the law defines as criminal (plausibly, because it produces a negative externality). By committing this act the individual becomes a criminal and, as such, faces some expected punishment. How high such expected punishment is depends on the judicial system the individual is subject to, e.g., whether it is a common law system or 
a civil code system. Of course an individual may not be detected, he may not get convicted, he may even bribe his way out. However, under a minimally functioning judicial system, in terms of lost utility, his expected punishment will be strictly positive, and the punishment imposed is independent of the individual in question: the law is by definition general.

In contrast, when considering the international public law governing international relations, countries perceive that they have some ability to actually influence both its design as well as its enforcement. For example, a country committing an act of war might violate international law and will face a given expected punishment. However, depending on the extent to which its allies and enemies can exert power in the international arena, and depending on the economic, military and political interests affected by both the act of war and its punishment, it may well be the case that an international agency such as the UN is unable to enforce the rules governing international relations in this specific case. One can even regard the expected punishment as dependent on the country in question, and as being insignificant in many instances. $^{2}$

Finally, we should note that the situation analyzed in our paper, where two conflicting parties invest resources in weaponry so as to defend their own endowment of productive capacity and possibly appropriate the other's, being then be subject to sanctions imposed by third parties, is somewhat different from a situation of 'anarchy' in international relations as defined and analyzed by Hirshleifer (1995a, 1995b).

Even though we recognize the role that a 'rally around the flag' effect can have in reducing the effectiveness of sanctions, we propose in our paper an alternative explanation for such reduced effectiveness. Our explanation has to do with a 'buy allies' effect in the international political market, according to which a target country tries to buy opposition to the imposition of sanctions by making use of its role as an importer of weapons from at least some of the very same third countries that would carry out the imposition of sanctions.

The paper goes as follows: the basic model is introduced in section 2 , 
and the political market for sanctions is discussed in section 3. Section 4 concludes the paper with some final remarks.

\section{Modeling Conflict and Third Party Inter- vention}

Our paper brings together two strands in the economics literature: the theory on conflict and rent-seeking and the theory on economic sanctions.

Firstly, Hirshleifer's 1988 seminal paper on the economic analysis of conflict studies the allocation of resources among appropriative and productive activities in an economy. Both Hirshleifer (1988, 1989, 1991a) and Garfinkel (1990) study different conflict technologies and their implications for an economy's resource allocation. Grossman and Kim (1995) develop a general equilibrium model to analyze the allocation of resources among appropriative and productive activities by two conflicting economic agents where the technology of conflict explicitly considers defensive and offensive activities. However, the strategic relation between the two conflicting parties is self-contained: by ignoring the rest of the world their model cannot deal with third party interventions such as conflict mediation and the possible imposition of sanctions as we do in this paper. Neary (1997) develops a game theoretical model of a two-player society where only armed self-enforcement of property rights is possible. However, and similarly to Grossman and Kim (1995), the strategic relation between the two conflicting parties is self-contained, hence ignoring third party interventions and their possible uselfulness in reducing the likelihood of conflict.

Secondly, Kaempfer and Lowenberg $(1988,1989)$ and Leidy (1989) present a public choice view of international economic sanctions. Based on Becker's theory of pressure groups (see Becker, 1983 and 1985), they construct a game between conflicting interest groups within both sending countries and target countries to determine the nature and level of sanctions. However, theirs is not an analysis of conflict between different parties fighting for some 
prize, who have to choose between investment in arms and investment in civilian productive capacity. It is solely an analysis of international economic sanctions in response to a conflict taken as given. Similarly, Eaton and Engers (1992) present a multi-stage game theoretic model of sanctions, where the players are the sender and the target of sanctions. They examine the potential for sanctions to elicit from the target of sanctions behavior deemed desirable by the sender. Theirs is a paper solely on sanctions, where the only interaction analyzed is the one between sender and target, and they ignore the public-goods issues raised by the existence of multiple senders; they also ignore the issues that arise when distinct groups within a sender country have conflicting interests.

We develop a model similar to the one in Grossman and Kim (1995). Each country acts as a self-interested economic agent who invests a given endowment on offensive or predatory activities, on defensive activities, and on directly productive activities. We assume that investments on offensive activities by at least one country might lead to conflict. We call this conflict war, but it may be seen generally as a bargaining game with strictly positive transaction costs. ${ }^{3}$ The UN, and international public law, aim at reducing these transaction costs by threatening to impose sanctions on countries which engage in offensive activities. In other words, aggressive policies are punished by supranational institutions such as the UN.

Following Kaempfer and Lowenberg (1988), we assume that the level of sanctions imposed on target countries is determined in a political market for sanctions where third countries, e.g. the countries represented in the UN, trade political influence. We show that a lower sanctions could be more effective in reducing transaction costs. This result comes from the interaction between players in the international political market, so that a higher sanction can exacerbate the military conflict, not reduce it. ${ }^{4}$ 


\subsection{The war game played by the conflicting parties}

In this section we construct a general model that tries to capture a situation where international property rights over resources are entirely defined by international public law, and where there exists a supranational agency that enforces them. Alternatively, we can interpret international public law as a system of behavioral norms or shared ethical beliefs performing the same function as international property rights.

A non-cooperative game is played by the political representatives of two countries $a$ and $b$. Each country $i=a, b$ is endowed with a finite resource $\omega_{i}>0$, and decides on the division of $\omega_{i}$ between investment in civilian productive capacity $e_{i} \geq 0$ and in military unproductive capacity $m_{i} \geq 0$. Capacity $e_{i}$ is used to produce final consumption goods according to some technology to be specified later. Investment $m_{i}$ can be either of an offensive type, denoted by $o_{i} \geq 0$, or of a defensive type, denoted by $d_{i} \geq 0$. Hence, $\omega_{i} \geq e_{i}+d_{i}+o_{i}$. This dichotomy of military expenditures has been justified in the literature. ${ }^{5}$

After these investments have been made, each country decides whether to engage in predation using its offensive weapons. Military expenditures are unproductive in that they are not inputs into the production of final consumption goods. However, because they can be used to defend one's capacity $e_{i}$ or appropriate the other country's capacity $e_{j}$, they can be seen as indirectly productive investment. In Grossman and Kim (1995), player $i$ can appropriate the other player's entire endowment $\omega_{j}$, regardless of how it has been allocated. Hence, both defensive and offensive military investments can be appropriated alongside with a country's civilian productive capacity. Alternatively, we can argue that, in a world where predatory activities take place only once, as it is the case in our model, there is no benefit in using up resources to appropriate military capacity belonging to one's opponent, since there will be no opportunity to use them. Nevertheless, in this general model we allow for any of these two cases.

The proportion of its own capacity that country $i$ is able to retain, be it 
its total endowment $\omega_{i}$ or its civilian productive capacity $e_{i}$ only, is a function $p_{i}$ of investments $d_{i}$ and $o_{j}$. Furthermore, the proportion of country $j$ 's own capacity that country $i$ is able to appropriate is a function $q_{i}$ of investments $d_{j}$ and $o_{i}$. For $i, j=a, b$ and $i \neq j$ we assume that:

(1) $p_{i}\left(d_{i}, 0\right)=1$ for all $d_{i} \geq 0 ; p_{i}\left(0, o_{j}\right)=0$ for all $o_{j}>0$;

(2) Functions $p_{i}$ and $q_{i}$ are in $C^{1}$, and $\frac{\partial p_{i}}{\partial d_{i}}>0, \frac{\partial p_{i}}{\partial o_{j}}<0, \frac{\partial q_{i}}{\partial d_{j}}<0, \frac{\partial q_{i}}{\partial o_{i}}>0$, $\frac{\partial^{2} p_{i}}{\partial d_{i}^{2}}<0$, and $\frac{\partial^{2} q_{i}}{\partial o_{i}^{2}}<0$;

(3) $q_{i}\left(0, o_{i}\right)=1$ for all $o_{i}>0 ; q_{i}\left(d_{j}, 0\right)=0$ for all $d_{j} \geq 0$;

(4) $0 \leq p_{i}\left(d_{i}, o_{j}\right)+q_{j}\left(d_{i}, o_{j}\right) \leq 1$.

All these assumptions are self-explanatory. The last two inequalities in condition (2) state that one's own investments in defensive and in offensive weapons exhibit decreasing returns. The second inequality in condition (4) can be interpreted as saying that predation can be destructive. In this case it would be illustrative to interpret predation as a form of exchange with transaction costs higher than in trade, i.e., in fully voluntary exchange. Functions $p_{i}$ and $q_{i}, i=a, b$, define what is known as a technology of conflict.

For any given profile $\left(\left(d_{i}, o_{i}\right) ;\left(d_{j}, o_{j}\right)\right)$, the value $p_{i}\left(d_{i}, o_{j}\right)$ can be interpreted either as the proportion of country $i$ 's capacity retained by country $i$, or the (discrete case) probability that country $i$ will retain its capacity, with $\left(1-p_{i}\right)$ denoting then the probability of country $i$ retaining zero capacity. Similarly, the value $q_{i}\left(d_{j}, o_{i}\right)$ can be interpreted either as the proportion of country $j$ 's capacity appropriated by country $i$, or the (discrete case) probability that country $i$ will appropriate country $j$ 's capacity, with $\left(1-q_{i}\right)$ denoting the probability of country $i$ appropriating none of country $j$ 's capacity. The probabilistic interpretation allows one to view the outcome of a conflict between different parties as uncertain - see Skaperdas (1991) - but under this interpretation $p_{i}\left(d_{i}, o_{j}\right)+q_{j}\left(d_{i}, o_{j}\right) \equiv 1$. Under the other interpretation, proportions $p_{i}$ and $q_{i}, i=a, b$, could be regarded as the outcome of some negotiation process between the two countries which takes into account their relative military strengths. 
Both countries might be the target of sanctions imposed by third countries. We assume that the level of sanctions is a monotonically increasing function $Z_{i}: \Re \rightarrow \Re$ of the investment level $o_{i}$ in offensive weapons made by country $i$. In particular, we will assume that sanctions take the form of a per unit $\operatorname{tax} z_{i}>0$ on the level of investment $o_{i}$. Then, $Z_{i}\left(o_{i}\right)=z_{i} \times o_{i}$. In the context of our model it is natural to assume that sanctions target only investments in offensive weapons. Investments in defensive weapons are not regarded as jeopardizing peace. Sanction policy $Z_{i}$ is public information.

In addition, we envision a split in country $i$ 's population between 'doves' and 'hawks'. This split tries to capture in a simple way the difference in preferences towards international relations between 'pacifists' and 'expansionists' within a country. It will allow us to study the impact of a change in country $i$ 's foreign policy, brought about by a change in the relative degrees of political influence exerted by doves and hawks, on the equilibrium investment levels $d_{i}, o_{i}$, and $d_{j}, o_{j}$ and, hence, on the distribution of resources in equilibrium.

We assume all doves in country $i$ have an identical preference relation $\succeq_{i}^{\text {dove }}$ over the set of profiles $\left(\left(e_{i}, d_{i}, o_{i}\right) ;\left(e_{j}, d_{j}, o_{j}\right)\right)$ such that they care exclusively about the preservation of their own country's productive capacity. Similarly, we assume all hawks have an identical preference relation $\succeq_{i}^{\text {hawk }}$ over that same set of profiles. However, hawks are assumed to care as much about the preservation of their own country's productive capacity as appropriating the other country's productive capacity in that they regard both as perfect substitutes. Hence, a dove in country $i$ ranks as his top alternative the complete preservation of his country's own productive capacity regardless of the proportion of country $j$ 's productive capacity country $i$ manages to appropriate. It follows that, between investments $d_{i}$ and $o_{i}$, a dove only cares about $d_{i}$.

We assume that doves and hawks exert political influence over their country's political decision-makers through the normal political process, such as periodical elections for the legislative, or executive, branches, as well as 
through other channels such as political lobbying. In this paper we will not make a distinction between these two types of political influence; the two groups are simply said to behave as political pressure groups in that they invest resources in steering the political decision-making process to work in their favor, be it through the vote or through less formalized political means. In effect, competition for political influence does not usually result in all-ornothing outcomes where one group, e.g. the winning majority in an election, clearly wins and another group clearly loses. Political influence can be extended well beyond the formal political process, be it the ballot box or not. Hence, even a minority group can be successful when attempting to influence in their favor the political decision-making process. It follows that even the preferences of a minority group might be reflected on the decision-maker's preferences.

Following Becker (1983, 1985), we assume that the degree of political influence exerted by each pressure group, doves or hawks, depends on its own size and on the size of the other group, on the amount of resources spent per each group member, and on other variables which will remain unspecified.

Let $I_{i}^{d}$ and $I_{i}^{h}$ denote the degrees of political influence exerted by doves and by hawks on country $i$ 's political decision-makers. Let $\mathcal{I}_{i} \equiv \frac{I_{i}^{d}}{I_{i}^{d}+I_{i}^{h}}$ denote the degree of relative political influence exerted by doves, where $I_{i}^{d} \geq 0, I_{j}^{d} \geq$ 0 , and $I_{i}^{d}+I_{j}^{d} \neq 0$. Then, $0 \leq \mathcal{I}_{i} \leq 1$, and the degree of relative political influence exerted by hawks equals $\left(1-\mathcal{I}_{i}\right)$.

For each given degree $\mathcal{I}_{i}$, country $i$ 's political representative has a preference relation $\succeq_{i}$ over the set of profiles $\left(\left(e_{i}, d_{i}, o_{i}\right) ;\left(e_{j}, d_{j}, o_{j}\right)\right)$, reflecting the degree of political influence exerted by doves and hawks in the population, and represented by a continuous and bounded utility function $\mathcal{U}_{i}$. We will abuse notation and will let $\mathcal{U}_{i}$ denote also $i$ 's utility function where $\mathcal{I}_{i}$ is taken as a parameter. Assume that function $\mathcal{U}_{i}$ is in $C^{2}$, and that:

(5) $\frac{\partial \mathcal{U}_{i}}{\partial e_{i}}>0$ for all $0 \leq \mathcal{I}_{i} \leq 1$;

(6) $\frac{\partial \mathcal{U}_{i}}{\partial e_{j}}=0$ for $\mathcal{I}_{i}=1$, and $\frac{\partial \mathcal{U}_{i}}{\partial e_{j}} \geq 0$ for all $0 \leq \mathcal{I}_{i}<1$;

(7) $\frac{\partial \mathcal{U}_{i}}{\partial e_{i}}>\frac{\partial \mathcal{U}_{i}}{\partial e_{j}}$ for all $0<\mathcal{I}_{i} \leq 1$; 
(8) $\frac{\partial^{2} \mathcal{U}_{i}}{\partial e_{j} \partial \mathcal{I}_{i}}<0$ for all $0 \leq \mathcal{I}_{i} \leq 1$;

(9) the Hessian matrix $H_{\left(d_{i}, o_{i}\right)}$ of second order partial derivatives of $\mathcal{U}_{i}$ with respect to $d_{i}$ and $o_{i}$ is negative definite everywhere in its domain.

Country $i$ is subject to a linear budget constraint $\mathcal{B}_{i}\left(e_{i}, o_{i}, d_{i}, z_{i}, \omega_{i}\right) \leq 0$, where:

(10) $\frac{\partial \mathcal{B}_{i}}{\partial \omega_{i}}<0, \frac{\partial \mathcal{B}_{i}}{\partial e_{i}}>0, \frac{\partial \mathcal{B}_{i}}{\partial o_{i}}>0, \frac{\partial \mathcal{B}_{i}}{\partial d_{i}}>0$, and $\frac{\partial \mathcal{B}_{i}}{\partial z_{i}}>0$, for all $e_{i}, o_{i}, d_{i}, z_{i}, \omega_{i} \geq 0$.

Given $o_{i}, d_{i}$ and $\omega_{i}$, and parameter $z_{i}, e_{i}$ is uniquely determined. Both countries play a Cournot duopoly game, with country $i$ 's strategy space being given by $A_{i} \equiv O_{i} \times D_{i} \times E_{i}=\left\{\left(o_{i}, d_{i}, e_{i}\right) \in \Re_{+}^{3}: \mathcal{B}_{i} \leq 0\right\}$, and with $\mathcal{U}_{i}$ being its payoff function. Country $i$ 's optimization problem is as follows:

$\max _{e_{i}, o_{i}, d_{i}} \mathcal{U}_{i}\left(\left(e_{i}, d_{i}, o_{i}\right),\left(e_{j}, d_{j}, o_{j}\right) ; \mathcal{I}_{i}\right)$

subject to $\mathcal{B}_{i}\left(e_{i}, o_{i}, d_{i}, z_{i}, \omega_{i}\right) \leq 0$ and $\left(e_{j}, d_{j}, o_{j}\right)$ taken as given.

Clearly, $A_{i}$ is a non-empty, convex and compact subset of the Euclidean space $\Re_{+}^{3}$. Since by assumption the hessian matrix $H_{\left(d_{i}, o_{i}\right)}$ is negative definite, by the implicit function theorem one can derive country $i$ 's best-response functions $d_{i}^{B R}$, and $o_{i}^{B R}$. In addition, since function $\mathcal{U}_{i}$ is continuous in the space $\left(A_{i} \times A_{j}\right)$, by a well-known theorem in game theory ${ }^{6}$ the above game has a Nash equilibrium in pure strategies.

\subsection{An example: arms embargo}

In this next example we follow the literature by assuming that $p_{i}\left(d_{i}, o_{j}\right) \equiv$ $\frac{d_{i}}{d_{i}+\theta \cdot o_{j}}$, where $\theta \geq 0$ is a parameter measuring the effectiveness of offensive weapons against defensive ones. Ceteris paribus, the higher is $\theta$ the more effective are the opponent's offensive weapons against country $i$ 's defensive weapons and, hence, the lower is the proportion of productive capacity that country $i$ will be able to retain after a conflict. On the other hand, if $\theta=0$ then country $j$ 's offensive weapons are powerless against country $i$ 's defenses and, hence, country $i$ will be able to retain its entire capacity after a conflict, i.e., $p_{i}\left(d_{i}, o_{j}\right) \equiv 1$ and $q_{j}\left(d_{i}, o_{j}\right) \equiv 0$. Furthermore, we assume that $q_{j}\left(d_{i}, o_{j}\right)=$ 
$(1-\beta)\left(1-p_{i}\left(d_{i}, o_{j}\right)\right)$, where $0 \leq \beta \leq 1$ so as to capture the idea that predation can be destructive and, hence, lead to a deadweight loss - see assumption (4) in the previous section. The higher is $\beta$ the more destructive is predation. It follows that $q_{j}\left(d_{i}, o_{j}\right) \equiv \frac{(1-\beta) \cdot \cdot \cdot o_{j}}{d_{i}+\theta \cdot o_{j}}$. These two functions are examples of contest success functions in ratio form as defined in Hirshleifer (1989) in the context of rent-seeking competition between two different parties. Henceforth, let $\xi \equiv(1-\beta) \theta$.

Given an investment level $e_{i}$ in civilian productive capacity, a constant returns to scale technology enables the production of consumables in the amount $\left(\alpha \cdot e_{i}\right)$, where $\alpha>0$ is a productivity parameter assumed common to both countries. We assume that the output of consumables is not appropriable, i.e., subject to predation, by the other country. However, country $i$ 's civilian productive capacity as well as its defensive and offensive weapons are subject to appropriation by the other country.

In the absence of sanctions, country $i$ faces a budget constraint given by: $\mathcal{B}_{i}=e_{i}+d_{i}+o_{i}-\omega_{i} \leq 0$. For a fixed level of endowment $\omega_{i}$ this constraint defines $i$ 's action space $A_{i}$, over which $i$ maximizes the following functional $\mathcal{U}_{i}$, which is assumed linear in $e_{i}, \omega_{i}$, and $\omega_{j}$ :

$\mathcal{U}_{i}\left(\left(d_{i}, o_{i}, e_{i}\right) ;\left(d_{j}, o_{j}, e_{j}\right) ; \mathcal{I}_{i} ; \omega_{i}, \omega_{j}\right)=\alpha e_{i}+p_{i}\left(d_{i}, o_{j}\right) \cdot \omega_{i}+q_{i}\left(d_{j}, o_{i}\right) \cdot\left(1-\mathcal{I}_{i}\right) \cdot \omega_{j}$

We are assuming that the marginal value for country $i$ of one unit of country $j$ 's endowment appropriated by the former equals the degree of relative political influence exerted by hawks in $i$. This value varies between zero and one.

Finally, given assumption (5) above, we know that a solution to country $i$ 's optimization problem will satisfy the budget constraint $\mathcal{B}_{i} \leq 0$ with equality. Hence, for each given profile $\left(e_{j}, d_{j}, o_{j}\right)$, country $i$ 's optimization problem can be rewritten as a maximization problem over the space of profiles $\left(d_{i}, o_{i}\right)$.

In many instances where international sanctions have been imposed on countries engaged in a military conflict, these sanctions took the form of an 
embargo on the exports of weaponry to these countries - as examples we point out the cases of Bosnia and Angola. In this paper we will assume that an arms embargo cover only offensive weapons. International sanctions are interpreted here as a policy instrument aimed at discouraging investments in offensive weapons, whether or not war between the conflicting parties will actually break out. The imposition of an arms embargo leads to a rise in the cost of offensive weapons for the country targeted by sanctions. In order to make this assumption consistent with our previous view of each country's investments, we can interpret $o_{i}$ as the fraction of the initial endowment $\omega_{i}$ country $i$ apportions to the purchase of offensive weapons either from domestic producers or from abroad.

Assume then that an arms embargo imposed on country $i$ implies that, for an investment $o_{i}$ in offensive weapons, the fraction of the initial endowment $\omega_{i}$ country $i$ will have to apportion to the purchase of offensive weapons will be $\left(1+z_{i}\right) \times o_{i}$. Country $i$ 's problem can then be written as:

$\max _{d_{i}, o_{i}} \mathcal{U}_{i}\left(\left(d_{i}, o_{i}, e_{i}\right) ;\left(d_{j}, o_{j}, e_{j}\right) ; \mathcal{I}_{i} ; \omega_{i}, \omega_{j}\right)=\alpha \cdot e_{i}+p_{i}\left(d_{i}, o_{j}\right) \cdot \omega_{i}+q_{i}\left(d_{j}, o_{i}\right) \cdot\left(1-\mathcal{I}_{i}\right) \cdot \omega_{j}$ subject to $e_{i}=\omega_{i}-d_{i}-\left(1+z_{i}\right) \cdot o_{i}$.

First-order necessary conditions for an interior maximum are:

$$
\begin{aligned}
& \frac{\partial \mathcal{U}_{i}}{\partial d_{i}} \equiv \frac{\partial p_{i}}{\partial d_{i}} \cdot \omega_{i}-\alpha=0, \\
& \frac{\partial \mathcal{U}_{i}}{\partial o_{i}} \equiv \frac{\partial q_{i}}{\partial o_{i}} \cdot \omega_{j} \cdot\left(1-\mathcal{I}_{i}\right)-\left(1+z_{i}\right) \cdot \alpha=0 .
\end{aligned}
$$

Second order sufficient conditions for a maximum are also satisfied. In fact, function $\mathcal{U}_{i}$ is strictly concave in the space of profiles $\left(d_{i}, o_{i}\right)$, for all $d_{j}, o_{j}>0$. Hence, the above (local) maximum is unique.

The Cournot-Nash equilibrium is given by a profile $\left(\left(d_{a}^{N E}, o_{a}^{N E}\right) ;\left(d_{b}^{N E}, o_{b}^{N E}\right)\right)$ where:

$$
d_{i}^{N E}=\frac{\left(1+z_{j}\right)\left(1-\mathcal{I}_{j}\right) \xi \omega_{i}}{\alpha\left[1+z_{j}+\left(1-\mathcal{I}_{j}\right) \xi\right]^{2}}
$$




$$
o_{i}^{N E}=\frac{\left(1-\mathcal{I}_{i}\right)^{2} \xi^{2} \omega_{j}}{\alpha \theta\left[1+z_{i}+\left(1-\mathcal{I}_{i}\right) \xi\right]^{2}}
$$

with $i=a, b$. Furthermore, $e_{i}^{N E}=\omega_{i}-\left(1+z_{i}\right) \cdot o_{i}^{N E}-d_{i}^{N E}$. It follows that $\frac{\partial o_{i}^{N E}}{\partial z_{i}}<0, \frac{\partial d_{i}^{N E}}{\partial z_{i}}=\frac{\partial o_{j}^{N E}}{\partial z_{i}}=0$. The signs of $\frac{\partial d_{j}^{N E}}{\partial z_{i}}, \frac{\partial e_{i}^{N E}}{\partial z_{i}}$, and of $\frac{\partial e_{j}^{N E}}{\partial z_{i}}$ are ambiguous. Hence, we can state the following result:

Proposition 1 An increase in the arms embargo rate $z_{i}$ targeting country $i$ will lead to a decrease in the equilibrium level of investment $o_{i}^{N E}$ in offensive weapons, but will have no effect on the equilibrium level of investment $d_{i}^{N E}$ in defensive weapons or on the equilibrium level of investment $o_{j}^{N E}$ in offensive weapons by the other country. Furthermore, it will have an ambiguous effect on country $j$ 's equilibrium level of investment $d_{j}^{N E}$ in defensive weapons, on country $i$ 's equilibrium level of civil capacity $e_{i}^{N E}$ and on country j's equilibrium level of civil capacity $e_{j}^{N E}$.

Proof: The unambiguous effects result immediately from the Cournot-Nash solution. As for the ambiguous effects one can easily show that the sign of $\frac{\partial d_{j}^{N E}}{\partial z_{i}}$ is the sign of the term $\left(1-\mathcal{I}_{i}\right) \cdot \xi-\left(1+z_{i}\right)$, and the sign of both $\frac{\partial e_{i}^{N E}}{\partial z_{i}}$ and $\frac{\partial e_{j}^{N E}}{\partial z_{i}}$ is the sign of the term $\left(1+z_{i}\right)-\left(1-\mathcal{I}_{i}\right) \cdot \xi$.QED

Proposition 1 tells us that the imposition of an arms embargo on country $i$ is always effective in that it always leads to a reduction on country $i$ 's equilibrium level of investment in offensive weapons, but it leaves the equilibrium level of investment in defensive weapons unchanged, since in this example both investments are independent - note that the second order cross derivative is zero. However, the effect on the equilibrium level of investment in productive capacity is ambiguous since there are two partial effects moving in opposite directions. An increase in the cost of offensive weapons due to the imposition of an embargo results, ceteris paribus, in less endowment being invested in productive capacity. On the other hand the level of investment in offensive weapons decreases, releasing endowment for investment in productive capacity. Which effect dominates depends on the relation between $z_{i}, \mathcal{I}_{i}$ 
and $\xi$ represented by the term $\left(1+z_{i}\right)-\left(1-\mathcal{I}_{i}\right) \cdot \xi$. The first effect will tend to dominate the second one when the sanction rate $z_{i}$ is small, the degree $\mathcal{I}_{i}$ of relative political influence exerted by doves is small, and the technology parameter $\xi$ is large. And since $\xi \equiv(1-\beta) \cdot \theta$, this means that $\xi$ is larger the less destructive is predation and the higher is the effectiveness of offensive weapons against defensive ones.

The effect of an increase in $z_{i}$ on country $j$ 's equilibrium investment in defensive weapons is also ambiguous. From the first-order condition it is clear that it depends on the marginal probability $\frac{\partial p_{j}}{\partial d_{j}}$ which may increase or decrease with $o_{i}$. Country $j$ 's investment in defensive weapons is more likely to decrease if the sanction $z_{i}$ is large, the degree $\mathcal{I}_{i}$ of relative political influence exerted by doves is large, and the technology parameter $\xi$ is small.

Finally, notice that an increase in the endowment level $\omega_{j}$ increases the equilibrium level of investment $o_{i}^{N E}$, since it increases its value at the margin relative to the investment $e_{i}$. An increase in $\omega_{j}$ also leads to an increase in $d_{j}$ such that the final effect on proportion $p_{j}$ is null, i.e., in equilibrium $\frac{\partial p_{j}}{\partial \omega_{j}}=0$. In other words, a wealthier country is as vulnerable to endowment appropriation as a poorer one, which means that the so-called "paradox of power" as defined in Hirshleifer (1991b) does not occur.

The next two propositions refer to the effect of a change in the degree $\mathcal{I}_{i}$ on the different equilibrium investments levels in both countries.

Proposition 2 An increase in the degree $\mathcal{I}_{i}$ of relative political influence exerted by doves in country $i$ results in a decrease in the equilibrium level of investment $o_{i}^{N E}$ in offensive weapons and an increase in the equilibrium level of civil capacity $e_{i}^{N E}$, but will have no effect on the equilibrium level of investment $d_{i}^{N E}$ in defensive weapons or on the equilibrium level of investment $o_{j}^{N E}$ in offensive weapons by the other country. Furthermore, it will have an ambiguous effect on country $j$ 's equilibrium level of investment $d_{j}^{N E}$ in defensive weapons and equilibrium level of civilian productive capacity $e_{j}^{N E}$.

Proof: The unambiguous effects result immediately from the Cournot-Nash solution. As for the ambiguous effects, we know that the sign of $\frac{\partial d_{j}^{N E}}{\partial \mathcal{I}_{i}}$ is the 
sign of the term $\left(1-\mathcal{I}_{i}\right) \cdot \xi-\left(1+z_{i}\right)$, and the sign of $\frac{\partial e_{j}^{N E}}{\partial \mathcal{I}_{i}}$ is the sign of the term $\left(1+z_{i}\right)-\left(1-\mathcal{I}_{i}\right) \cdot \xi$.QED

Note the similarity between an increase in the arms embargo rate $z_{i}$ and an increase in the degree $\mathcal{I}_{i}$ of relative political influence exerted by doves in country $i$. There is just one difference, namely that an increase in the degree $\mathcal{I}_{i}$ always induces more investment in productive capacity, while the same is not true with an arms embargo.

Proposition 1 and 2 show that an increased sanctions rate $z_{i}$ and a larger degree $\mathcal{I}_{i}$ of relative political influence exerted by doves in country $i$ will have similar effects on the equilibrium levels of investment in both offensive and defensive weapons in both countries. Hence, the promotion of education and other social policies aimed at increasing the proportion of doves in the population can be regarded as an alternative, and effective, conflict deterrent to the imposition of an arms embargo on conflicting countries.

Proposition 3 An increase in the degree $\mathcal{I}_{i}$ of relative political influence exerted by doves in country $i$ will result in a decrease in country $j$ 's equilibrium level of investment $d_{j}$ in defensive weapons if and only if $\frac{1+z_{i}}{1-\mathcal{I}_{i}}>\xi$. Similarly, an increase in the arms embargo rate $z_{i}$ targeting country $i$ will result in a decrease in country $j$ 's equilibrium level of investment $d_{j}$ in defensive weapons if and only if $\frac{1+z_{i}}{1-\mathcal{I}_{i}}>\xi$. Moreover, $\frac{1+z_{i}}{1-\mathcal{I}_{i}}>\xi$ if and only if $p_{j}^{N E}>1 / 2$.

Proof: From the Cournot-Nash solutions we immediately obtain the partial derivatives $\frac{\partial d_{j}^{N E}}{\partial \mathcal{I}_{i}}$ and $\frac{\partial d_{j}^{N E}}{\partial z_{i}}$. Moreover, it is easy to show that $p_{j}^{N E}=$ $\frac{1+z_{i}}{1+z_{i}+\left(1-\mathcal{I}_{i}\right) \xi}$. Hence, $\frac{1+z_{i}}{1-\mathcal{I}_{i}}>\xi$ if and only if $p_{j}^{N E} \geq 1 / 2$.QED

This proposition gives some content to the ambiguous result derived before. Consider the impact of an increased arms embargo rate $z_{i}$ on country $j$ 's investment in defensive weapons. One could be tempted to argue that, given that the enemy is investing less in offensive weapons, country $j$ would invest less in defense and more in productive activities. However it may also be the case that it is now more attractive to invest in securing $\omega_{j}$ because 
Table 1: Comparative statics (Propositions 1,2 \& 3)

\begin{tabular}{|l|cccccccc|}
\hline & $d_{i}^{N E}$ & $o_{i}^{N E}$ & $e_{i}^{N E}$ & $d_{j}^{N E}$ & $o_{j}^{N E}$ & $e_{j}^{N E}$ & $p_{i}^{N E}$ & $p_{j}^{N E}$ \\
\hline$z_{i} \nearrow$ & $\rightarrow$ & $\searrow$ & $?$ & $?$ & $\rightarrow$ & $?$ & $\rightarrow$ & $?$ \\
\hline $\mathcal{I}_{i} \nearrow$ & $\rightarrow$ & $\searrow$ & $\nearrow$ & $?$ & $\rightarrow$ & $?$ & $\rightarrow$ & $\nearrow$ \\
\hline$\omega_{i} \nearrow$ & $\nearrow$ & $\rightarrow$ & $\rightarrow$ & $\rightarrow$ & $\nearrow$ & $\searrow$ & $\rightarrow$ & $\rightarrow$ \\
\hline
\end{tabular}

it is cheaper to do so. Hence, spending more in securing $\omega_{j}$ and less in productive activities can be optimal. From Proposition 3, we know that the first argument applies if $p_{j}^{N E}>1 / 2$, whereas the second argument applies if $p_{j}^{N E}<1 / 2$.

Table 1 summarizes the three propositions discussed before. An upward slopped arrow means an increase, a downwards slopped arrow means a decrease, an horizontal slopped arrow means no change, and a question mark means an ambiguous result.

In this example it is clear that sanctions are always a deterrent to investing in offensive weapons and, hence, they behave as a conflict deterrent. Moreover, as $z_{i} \rightarrow \infty$, i.e., as the arms embargo becomes tougher, the equilibrium level of investment in offensive weapons tends to zero, i.e., $o_{i}^{N E} \rightarrow 0$. This summarizes the argument for the imposition of arms embargoes. In the next section we attempt to show that this argument is naïve.

\section{The international political market}

The public choice approach to international organizations has been typically characterized by a constitutional or social contract view under which the underlying players are regarded as sovereign, but where their individual selfinterested behavior leads to a Pareto inefficient outcome. Military and trade wars can be regarded as international public bads in that they impose negative externalities. There is no world authority that can effectively control the behavior of countries in their selfish pursuit of their own interests. A Pareto-optimal outcome can only come about by a certain degree of consen- 
sus among nations - for a survey of these arguments see Frey (1997).

Our view is that the constitutional contract is in reality the outcome of a bargaining process in which countries act to further their own selfish interests. This contract is not necessarily Pareto efficient. We show that the problem is not the contract in itself - sanctions were always effective in the previous section - but, instead, the bargaining process resulting in a 'trade of political influence'.

The level of sanctions imposed on countries $a$ and $b$ are seen as an equilibrium outcome of an international political game played by a large group of countries. This political game is modeled as a political market for sanctions as in Kaempfer and Lowenberg (1988), where different countries, possibly having different (social) preferences over the imposition of sanctions, 'trade political influence'. This point of view will regard international organizations such as the UN as embodying a political market for sanctions. Even though we recognize that different countries have different degrees of influence within the UN - in particular, in the UN Security Council the five permanent members have a veto power over some issues - at this stage of the analysis we will assume that all countries behave as perfect competitors in the market for political influence. An alternative approach would recognize that a small group of countries behave very much like a group of dominant firms (or as oligopolists), with smaller countries behaving like a competitive fringe. Note that even in this case the qualitative results presented in the paper will hold. ${ }^{7}$

As for choosing countries as our units of analysis, i.e., as individual selfinterested economic agents, possibly a more realistic alternative viewpoint would recognize that within each country there are pressure groups with different preferences over the imposition of sanctions on target countries. A useful dichotomy would distinguish between 'interventionists' and 'isolationists'. For example, this dichotomy applies easily to the USA before, if not during, their involvement in the two world wars.

One way of justifying this dichotomy is to recognize that sanctions might serve the interests of some (pressure) groups and run counter the interests 
of other (pressure) groups, within each sending country. For example, we could regard interventionists as domestic producers that will benefit from the imposition of sanctions taking the form of a ban on imports from the target countries, and isolationists as domestic producers that will be hurt by the imposition of sanctions which take the form of a ban on exports to the target countries as in Kaempfer and Lowenberg (1988). In any case, our approach can encompass this viewpoint by directly including all pressure groups from all different countries in the international political market for sanctions instead of viewing individual countries as our 'units of analysis'.

Following Kaempfer and Lowenberg (1988), let there be $N$ different countries divided in two different groups, $G_{1}$ and $G_{2}$, with $N_{1}$ and $N_{2}=(N-$ $N_{1}$ ) members. All countries in $G_{1}$ benefit from the imposition of sanctions whereas all countries in $G_{2}$ lose. Let $z_{i} \in \Re_{+}$measure the per unit level of sanctions imposed on country $i$ as a response to any strictly positive invesment level $o_{i}$, with $i=a, b$. For every given level of sanctions $z_{i} \in \Re_{+}$, each country $k$ in $G_{1}$ is willing to pay some price $p_{k, i}(z)$ for an additional unit of sanctions imposed on country $i$. Then, $\sum_{k \in G_{1}} p_{k, i}\left(z_{i}\right)$ for all $z_{i} \in \Re_{+}$defines an aggregate inverse demand function $P_{1, i}: \Re_{+} \rightarrow \Re_{+}$for additional sanctions, where $P_{1, i}\left(z_{i}\right)>0$ for all $z_{i} \in \Re_{+}$. Similarly, given every level of sanctions $z_{i} \in \Re_{+}$each country $m$ in $G_{2}$ is willing to pay some price $p_{m, i}\left(z_{i}\right)$ for one less unit of sanctions. $\sum_{m \in G_{2}} p_{m, i}\left(z_{i}\right)$ defines an aggregate inverse demand function $P_{2, i}: \Re_{+} \rightarrow \Re_{+}$for less sanctions, where $P_{2, i}\left(z_{i}\right)>0$ for all $z_{i} \in \Re_{+}$. We further assume that $\partial P_{1, i} / \partial z_{i}<0$ and $\partial P_{2, i} / \partial z_{i}>0$ for all $z_{i} \in \Re_{+}$. These two functions define a political market for sanctions; if an equilibrium $\left(P_{i}^{*}, z_{i}^{*}\right)$ exists it is clearly unique, and $z_{i}^{*}$ defines the level of sanctions that will be imposed on country $i$ as a result of her investment $o_{i}, i=a, b$. We will assume for now that the two international political markets are independent.

Figure 1 here

We take the view that the price $p_{k, i}(z)$ each country $k$ in $G_{1}$ is willing to pay for an additional unit of sanctions does not necessarily equal the sum, be 
it over all individual citizens or over all groups of citizens, of the prices, positive or negative, at which each member values an additional unit of sanctions. Rather, it is an average of all those different prices weighted by the degree of political effectiveness each member (e.g. each pressure group) is able to command when exerting influence over the country's political representatives. Therefore, even though the imposition of sanctions, by restricting free trade between the sending countries and the target countries, will create a deadweight loss for all senders taken together, it does not follow that the losers, i.e., countries in group $G_{2}$, will be able to buy out countries in group $G_{1}$ and avoid the imposition of sanctions altogether (see Kaempfer and Lowenberg (1988), following Becker's work on pressure groups and influence functions). This assumption can be interpreted as saying that the 'invisible hand' does not work for the case of interaction between pressure groups. Finally, we will continue to assume that $p_{i}\left(d_{i}, o_{j}\right) \equiv \frac{d_{i}}{d_{i}+\theta \cdot o_{j}}$ and that $q_{i}\left(d_{j}, o_{i}\right) \equiv \frac{\xi \cdot o_{i}}{d_{j}+\theta \cdot o_{i}}$, where $\theta \geq \xi \geq 0$.

\subsection{Trade in Weapons}

For the case of an arms embargo being imposed on countries $a$ and $b$, assume that group $G_{2}$ comprises the countries exporting weapons to $a$ and $b$. Hence, it is reasonable to assume that countries in $G_{2}$ will be hurt by the imposition of economic sanctions which, directly (as in the case of arms embargoes) or indirectly, will affect their exports of weaponry. It follows they are willing to pay a price to prevent the imposition of sanctions. This price is assumed to increase with an increase in the level of per unit sanctions $z_{i}$. Moreover, the greater is the pre-embargo volume of weapons exported to both conflicting countries by the members of $G_{2}$ the higher is the price the latter are willing to pay to prevent the imposition of per unit sanctions $z_{i}$ - see van Bergeijk (1989).

On the other hand, by investing in offensive weapons, country $i$ will try to 'buy allies' in the international political market. We model this effect by assuming that there exists a continuous mapping $o_{i} \stackrel{\phi}{\longmapsto} P_{2, i}^{o_{i}}$, with $\phi\left(o_{i}\right)>0$ for 
all $o_{i} \geq 0$, where $P_{2, i}^{o_{i}}: \Re_{+} \rightarrow \Re_{+}$denotes the (redefined) aggregate demand function for less sanctions by group $G_{2}$. Hence, for each level of investment $o_{i}$ and for each level of sanctions $z_{i}, P_{2, i}^{o_{i}}\left(z_{i}\right)$ denotes the maximum price group $G_{2}$ as a whole is willing to pay for one less unit of sanctions imposed on country $i$. An increase in $o_{i}$ leads to an upward shift of the "demand" curve $P_{2, i}$ to $P_{2, i}^{\prime}$, whereas a decrease in $o_{i}$ leads to a downward shift of this same "demand" curve - see figure 1.

Given some sanctioning policy $\left(z_{a}, z_{b}\right)$, country $i$ 's problem can be written as:

$$
\begin{aligned}
& \max _{d_{i}, o_{i}} \mathcal{V}_{i}\left(\left(e_{i}, d_{i}, o_{i}\right),\left(e_{j}, d_{j}, o_{j}\right) ; \mathcal{I}_{i} ; \omega_{i}, \omega_{j}\right)= \\
& \alpha \cdot e_{i}+p_{i}\left(d_{i}, o_{j}\right) \cdot \omega_{i}+q_{i}\left(d_{j}, o_{i}\right) \cdot\left(1-\mathcal{I}_{i}\right) \cdot \omega_{j} \\
& \text { subject to } e_{i}=\omega_{i}-d_{i}-\left(1+z_{i}\left(o_{i}\right)\right) \cdot o_{i} .
\end{aligned}
$$

First-order necessary conditions for an interior maximum are:

$$
\begin{aligned}
& \frac{\partial \mathcal{V}_{i}}{\partial d_{i}} \equiv \frac{\partial p_{i}}{\partial d_{i}} \cdot \omega_{i}-\alpha=0, \\
& \frac{\partial \mathcal{V}_{i}}{\partial o_{i}} \equiv \frac{\partial q_{i}}{\partial o_{i}} \cdot \omega_{j} \cdot\left(1-\mathcal{I}_{i}\right)-\left(1+z_{i}\right) \cdot \alpha-z_{i} \cdot \frac{\partial z_{i}}{\partial o_{i}} \cdot \alpha=0 .
\end{aligned}
$$

Under the assumptions made before, a second order sufficient condition for a unique maximum is satisfied. In this case $o_{i}^{N E}$ is usually larger than in section 2.2. due to a 'buying allies' effect. Take the elasticity $-\frac{\partial z_{i}}{\partial o_{i}} \frac{o_{i}}{z_{i}}$ and suppose $-\frac{\partial z_{i}}{\partial o_{i}} \frac{o_{i}}{z_{i}}=\gamma_{i}$, for $i=a, b$ and where $\gamma_{i}$ is some positive constant. The Cournot-Nash equilibrium is given by a profile $\left.\left(\left(d_{a}^{N E}, o_{a}^{N E}\right)\right) ;\left(d_{b}^{N E}, o_{b}^{N E}\right)\right)$ where:

$$
\begin{aligned}
d_{i}^{N E} & =\frac{\left[1+z_{j}\left(1-\gamma_{j}\right)\right]\left(1-\mathcal{I}_{j}\right) \xi \omega_{i}}{\alpha\left[1+z_{j}\left(1-\gamma_{j}\right)+\left(1-\mathcal{I}_{j}\right) \xi\right]^{2}} \\
o_{i}^{N E} & =\frac{\left(1-\mathcal{I}_{i}\right)^{2} \xi^{2} \omega_{j}}{\alpha \theta\left[1+z_{i}\left(1-\gamma_{i}\right)+\left(1-\mathcal{I}_{i}\right) \xi\right]^{2}}
\end{aligned}
$$

for $i=a, b$. It then follows that $e_{i}^{N E}=\omega_{i}-\left(1+z_{i}\left(o_{i}^{N E}\right)\right) \cdot o_{i}^{N E}-d_{i}^{N E}$. 
Comparing (2) and (4), it is clear that as long as $\gamma_{i}>0$, i.e., as long as some trading takes place in the political market, an arms embargo will be less effective than what the naïve view claims - see proposition 1 . When $\gamma_{i}>1$, one should not impose an arms embargo at all because it creates an overshooting of investment in offensive weapons, hence exacerbating the conflict. The next proposition summarizes these results:

Proposition 4 In the presence of an international political market, an increase in the arms embargo rate $z_{i}$ targeting country $i$ will lead to the same qualitative effects as in proposition 1, but these effects will be smaller. However, if $\gamma_{i}>1$ then an increase in the arms embargo rate $z_{i}$ targeting country $i$ will lead to an increase in country $i$ 's equilibrium level of investment $o_{i}^{N E}$ in offensive weapons.

Proof: Obvious from an examination of the Nash equilibrium above, and from its comparison with the Nash equilibrium from section 2.2.QED

\section{Final remarks}

In this paper, we have extended the current economic theory of conflict and anarchy to a situation where property rights exist, can be enforced, but are subject to a previous bargaining game between the lawbreakers and the enforcers. We have developed the argument that the existence of these sanctions can exacerbate the conflict because both parties use their resources to 'buy' the enforcers.

A related question is how to measure the success and failure of international sanctions. In his 1989 paper, van Bergeijk concludes that the probability that an economic sanction succeeds is higher the larger is the pre-sanction trade linkage (between target country and sender country(ies)), the more unstable the target's political situation and the shorter the sanction period. The results support the idea that prolonged duration of a sanction decreases its efficacy. His investigation answers affirmatively to the question of whether 
economic sanctions can be effective instruments in international politics - see also Diehl et. al. (1996).

We have taken the view that sanctions aim at reducing investment in aggressive activities or predation. The argument for limited sanctions has been constructed assessing the effectiveness of sanctions as conflict deterrents. An alternative view would be to argue that sanctions aim at inducing the substitution of investment in aggressive activities by investment in civil productive capacity. The model shows that if that is the aim, an education and social policy aiming at increasing the proportion of doves (those who do not like war) in a given country is more effective than a sanctioning policy. This suggests some support to the recent proposals of investing more in UNESCO and similar organizations rather than UN military forces.

A final aspect is the motivation of those acting in the political market: we have built the argument assuming that the preferences of national governments coincide with the preferences of the national delegates in the UN General Assembly. There has been some literature on the importance of these delegates' preferences - see Eaton and Engers (1992), Kaufman and Duncan (1992), and Frey (1997). The conclusions of our model can allow for differences on preferences: as long as we accept that the UN delegates engage on some trade of political influence where their votes can be bought, the model goes through.

Complementing recent literature by Downs, Rocke and Barsoon (1996) and Abbot and Snidal (1998), our paper suggests that the ineffectiveness of international sanctions is not necessarily due to an alleged (or perceived) under-policing but can be the consequence of over-policing and related avoidance activities.

\section{References}

Abbot, S. and Snidal, D. (1998). Why states act through formal international organizations. Journal of Conflict Resolution 42 (1): 3-32. 
Becker, G. (1983). A theory of competition among pressure groups for political influence. Quarterly Journal of Economics 98: 371-400.

Becker, G. (1985). Public policies, pressure groups and dead weight costs. Journal of Public Economics 28: 329-347.

van Bergeijk, P. (1989). Success and failure of economic sanctions. Kyklos 42 (3): 385-404.

Brito, D. and Intriligator, M. (1984). Can arms races lead to the outbreak of war. Journal of Conflict Resolution 28 (1): 63-84.

Brito, D. and Intriligator, M. (1985). Conflict, war, and redistribution, American Political Science Review 79: 943-957.

Bueno de Mesquita, B., and Lalman, D. (1988). Arms races and the opportunity for peace. Synthese 76: 263-283.

Diehl, P., Reifschneider, J., and Hensel, P. (1996). United Nations intervention and recurring conflict. International Organization 50 (4): 683-700.

Downs, G., Rocke, D., and Barsoon, P. (1996). Is the good news about compliance good news about cooperation? International Organization 50 (3): 379-406.

Eaton, J., and Engers, M. (1992). Sanctions. Journal of Political Economy 100 (5): 899-928.

Fearon, J. (1995). Rationalist explanations for war. International Organization 49 (3): 379-414.

Frey, B. S. (1997). The public choice of international organizations. In D. C. Mueller (Ed.), Perspectives on public choice: a handbook, 106-123. Cambridge, MA: Cambridge University Press.

Garfinkel, M. (1990). Arming as a strategic investment in cooperative equilibrium. American Economic Review 80: 1294-1309.

Glaser, C., and Kaufman, C. (1998). What is the offense-defense balance and can we measure it? International Security 22 (4): 44-82.

Grossman, H. and Kim, M. (1995). Swords or plowshares? A theory of the security of claims to property. Journal of Political Economy 103 (6): 1275-1288. 
Hirshleifer, J. (1988). The analytics of continuing conflict. Synthese 76: 201-233.

Hirshleifer, J. (1989). Conflict and rent-seeking success functions: ratio vs. difference models of relative success. Public Choice 63: 101-112.

Hirshleifer, J. (1991a). The technology of conflict as an economic activity. American Economic Review 81 (2): 130-134.

Hirshleifer, J. (1991b). The paradox of power. Economics and Politics 3 (3): 177-200.

Hirshleifer, J. (1995a). Anarchy and its breakdown. Journal of Political Economy 103 (1): 26-52.

Hirshleifer, J. (1995b). Theorizing about conflict. In K. Hartley and T. Sandler (Eds.), Handbook of defense economics, 165-189. Amsterdam, The Netherlands: North-Holland/Elsevier Science.

Kaempfer, W. and Lowenberg, A. (1986). A model of the political economy of international investment sanctions: the case of South Africa. Kyklos 39 (3): 377-396.

Kaempfer, W. and Lowenberg, A. (1988). The theory of international economic sanctions: a public choice approach. American Economic Review 78 (4): 786-793.

Kaempfer, W. and Lowenberg, A. (1989). The theory of international economic sanctions - a public choice approach: reply. American Economic Review 79 (5): 1304-1306.

Kaufman, S. and Duncan, G. (1992). A formal framework for mediator mechanisms and motivations. Journal of Conflict Resolution 36 (4): 688708.

Leidy, M. (1989). The theory of international economic sanctions - a public choice approach: comment. American Economic Review 79 (5): 1300-1303. Neary, H. (1997). Equilibrium structure in an economic model of conflict. Economic Inquiry 35: 480-494.

O'Neill, B. (1994). Game theory models of war and peace. In R. Aumann and S. Hart (Eds.), Handbook of game theory, vol. II, 995-1053. Amsterdam, 
The Netherlands: North-Holland/Elsevier Science.

Pape, R. (1997). Why economic sanctions do not work. International Security 22 (2): 90-136.

Skaperdas, S. (1991). Conflict and attitudes toward risk. American Economic Review 81 (2): 116-120.

White, N. (1994). UN peacekeeping - development or destruction? International Relations 12: 129-158.

\section{Endnotes}

[1] In support of the first argument, Pape (1997) mentions Iraq - or the Iraqi regime - as an illustrative example of a target of sanctions which has, at least until now, shown a remarkable degree of endurance against what have been the most extreme package of sanctions ever have applied to a country in recent history. As an example supporting the latter argument it is often pointed out that the economic recession that apartheid and early post-apartheid SouthAfrica underwent due, at least partially, to the desinvestment that followed the imposition of international economic sanctions during the apartheid days, was especially harmful to more vulnerable economically, i.e., to the same people that were discriminated against by the apartheid regime. Also for a discussion of the South-African case see Kaempfer and Lowenberg (1986). [2] Examples: Indonesian occupation of East-Timor versus Iraqi occupation of Kuwait; the 1997 Turkish invasion of Iraqi Kurdistan; Angola, Rwanda and Burundi support to Kabila's rebels in Zaire (now Democratic Republic of Congo) versus South-African support to UNITA rebels in Angola. According to The Economist - see its November 16th, 1996 issue - Zairian rebels were boosted by the imposition of international sanctions on Burundi's military regime. According to this newspaper, these sanctions induced the Burundi's government to do nothing about guerrilla infiltration along the Zairian borders.

[3] We realize that investments in predation do not necessarily lead to war. 
Brito and Intriligator (1984, 1985), Bueno de Mesquita and Lalman (1988), and Fearon (1995) argue that investment in predation activities may deter actual predation: whether or not such investments will lead to war will typically depend on factors such as the player's beliefs about each other's military strength, their relative strength, and possibly many other factors one could subsume in a random term. A review of the literature can be found in O'Neill (1994).

[4] For example, on its 30th March 1996 issue, The Economist argued that the UN arms embargo in Bosnia exacerbated the conflict: both sides started bombing UN peacekeepers to endanger soldiers' lives and force them to go. [5] We are fully aware of the controversy surrounding such distinction between offensive and defensive weapons. See Glaser and Kauffman (1998) for a review of the so-called Offense-Defense theory.

[6] Debreu-Glicksberg-Fan Theorem.

[7] There are many options in modeling how decisions are taken in the UN. Some stylized facts can be observed: first, it is usually a majority rule; second, within this majority rule the size of the majority may vary according to the importance of the issue but it is usually a simply majority rule; in the General Assembly, we observe one vote per country. 